\title{
Is islet transplantation a realistic approach to curing diabetes?
}

\author{
Sang-Man Jin ${ }^{1}$ and Kwang-Won $\mathrm{Kim}^{2}$
}

\author{
${ }^{1}$ Division of Endocrinology and \\ Metabolism, Department of \\ Medicine, Samsung Medical Center, \\ Sungkyunkwan University School \\ of Medicine, Seoul; ${ }^{2}$ Division of \\ Endocrinology and Metabolism, \\ Department of Internal Medicine, \\ Gachon University Gil Medical Center, \\ Incheon, Korea
}

Received: June 30, 2016 Accepted: December 19, 2016

\section{Correspondence to}

Kwang-Won Kim, M.D.

Division of Endocrinology and Metabolism, Department of Internal Medicine, Gachon University Gil Medical Center, 21 Namdong-daero 774beon-gil, Namdong-gu, Incheon 21565,

Korea

Tel: $+82-32-460-8309$

Fax: $+82-32-469-4320$

E-mail: kwkim@gilhospital.com
Since the report of type 1 diabetes reversal in seven consecutive patients by the Edmonton protocol in 2000, pancreatic islet transplantation has been reappraised based on accumulated clinical evidence. Although initially expected to therapeutically target long-term insulin independence, islet transplantation is now indicated for more specific clinical benefits. With the long-awaited report of the first phase 3 clinical trial in 2016, allogeneic islet transplantation is now transitioning from an experimental to a proven therapy for type 1 diabetes with problematic hypoglycemia. Islet autotransplantation has already been therapeutically proven in chronic pancreatitis with severe abdominal pain refractory to conventional treatments, and it holds promise for preventing diabetes after partial pancreatectomy due to benign pancreatic tumors. Based on current evidence, this review focuses on islet transplantation as a realistic approach to treating diabetes.

Keywords: Islet; Islets of Langerhans transplantation; Diabetes; Hypoglycemia

\section{INTRODUCTION}

In the decade and a half since the Edmonton protocol report of 1-year insulin independence following pancreatic islet transplantation in seven consecutive type 1 diabetes mellitus patients [1], the position of islet transplantation in clinical medicine has been reappraised [25]. During this period, insulin therapy has dramatically improved through the introduction of newer insulin analogues and emerging technologies, such as the sensor-augmented insulin pump and closed-loop insulin delivery. The solitary pancreas whole-organ transplantation rate has decreased in the United States due to concerns that it confers no long-term survival benefits; however, the benefits of simultaneous kidney-pancreas transplantation are indisputable [6]. The long-term insulin-independence rate of clinical islet transplantation has been steadily improving in centers that have adopted potent induction immunotherapy [7].

Initially expected to target long-term insulin independence, islet transplantation therapy has been refined for more specific clinical benefits [5]. With the publication of the long-awaited report of the first phase 3 clinical trial, allogeneic islet transplantation is now transitioning from an experimental to a proven therapy with specific clinical indications [8]. Islet autotransplantation (IAT) is already a proven therapy in chronic pancreatitis with severe abdominal pain refractory to conventional 
treatments [9], and it also holds promise as an intervention for preventing diabetes after partial pancreatectomy for benign pancreatic tumors [10]. Based on current evidence, this review focuses on islet transplantation as a realistic approach to the treatment of diabetes.

\section{CURRENT STATUS OF ALLOGENEIC ISLET TRANSPLANTATION AS A TREATMENT FOR PROBLEMATIC HYPOGLYCEMIA}

In 2000, Shapiro et al. [1] at the University of Alberta in Edmonton reported the achievement of 1-year insulin independence by pancreatic islet transplantation in seven consecutive type 1 diabetes patients with severe hypoglycemia and intact renal function. The subsequent international clinical trial of the landmark "Edmonton protocol" achieved an important clinical outcome: an $\sim 80 \%$ success rate of maintaining glycated hemoglobin (HbAlc) levels at less than $7.0 \%$ for 5 years without severe hypoglycemia [11]. Although the single-donor insulin-independence rate of allogeneic islet transplantation is still inferior to that of whole-organ pancreas transplantation, with only a few exceptions in some experienced centers [12], the rates of protection from severe hypoglycemia associated with the allogeneic transplantation of islets or of the whole pancreas are comparable [13]. Although the prevalence of insulin independence 5 years after transplantation is $25 \%$ to $50 \%$ in most recent clinical trials of allogeneic islet transplantation, islet and pancreas transplantation are equally effective in curing severe hypoglycemia, achieving a success rate of about $70 \%$ after more than 5 years. Moreover, the success rate of islet transplantation in cases of islet-after-kidney transplantation, in which no additional maintenance immunosuppression is required for islet transplantation per se, is not inferior to that of islet transplantation alone (Table 1). Therefore, the latest treatment regimen for patients with type 1 diabetes and problematic hypoglycemia recommends islet or pancreas transplantation for patients with continuing severe hypoglycemia as the final component in a stepwise approach that includes structured education regarding multiple daily injections of insulin and technology such as sensor-augmented pumps with low glucose suspension [5].

Recently, the French-Swiss GRAGIL Network successfully reproduced the long-term outcome achieved with the Edmonton protocol in terms of the graft survival rate $(\sim 80 \%)$, with a $58 \%$ rate of HbA1c levels at < $7 \%$ and lack of severe hypoglycemia 5 years after islet transplantation [14]. Several cases of partial islet graft function have also been reported in Korea [15,16], with the first case of long-term insulin independence reported in late 2015. In 2016, a multicenter, single-arm, phase 3 clinical trial of allogeneic islet transplantation was reported. The primary endpoint of this study was the achievement of $\mathrm{HbAic}<7.0 \%$ at day 365 and freedom from severe hypoglycemic events from day 28 to day 365 after the first islet transplantation. The primary endpoint was successfully met by $87.5 \%$ of subjects at 1 year and by $71 \%$ at 2 years. The insulin-independence rate was $52 \%$ at 1 year and $42 \%$ at 2 years [8]. This study provides importance evidence for allogeneic islet transplantation as a proven rather than just an experimental therapy for problematic hypoglycemia and may provide a basis for U.S. Food and Drug Administration approval

Table 1. Current outcome of islet and pancreas whole organ transplantation

\begin{tabular}{|c|c|c|}
\hline & Islet transplantation & Pancreas transplantation \\
\hline Insulin independence rate & $\begin{array}{l}25 \%-50 \% \text { at } 5 \text { years in international } \\
\text { cohort studies }(\sim 50 \% \text { in some } \\
\text { experienced centers }[7,12])\end{array}$ & $70 \%$ at 5 years \\
\hline $\begin{array}{l}\text { Graft survival (fasting C-peptide > } \\
0.3 \mathrm{ng} / \mathrm{mL} \text {, free of severe hypoglycemia) }\end{array}$ & $\begin{array}{l}\sim 70 \% \text { at } 5 \text { years }(75 \% \text { at } 5 \text { years in } \\
\text { the French-Swiss GRAGIL group [14]) }\end{array}$ & $\sim 70 \%$ at 5 years \\
\hline $\begin{array}{l}\text { Success rate according to the clinical } \\
\text { setting }\end{array}$ & $\begin{array}{l}\text { Islet alone }=\text { islet after kidney = } \\
\text { simultaneous islet and kidney }\end{array}$ & $\begin{array}{l}\text { Simultaneous pancreas and kidney }> \\
\text { pancreas alone = pancreas after kidney }\end{array}$ \\
\hline Morbidity/mortality & $\begin{array}{l}\text { Very low procedure complication } \\
\text { rate, low mortality }\end{array}$ & $\begin{array}{l}\text { Perioperative morbidity, complications } \\
\text { of exocrine pancreas, and late surgical } \\
\text { complications }\end{array}$ \\
\hline
\end{tabular}


in the near future. The results of this trial have also led to medical insurance reimbursement for clinical allogeneic islet transplantation in patients with type 1 diabetes and problematic hypoglycemia.

Additionally, the clinical outcomes achieved in selected centers with extensive experience are already comparable to those of whole-pancreas transplantation in terms of 1- and 5-year insulin-independence rates, which were reported to be as high as $\sim 70 \%$ and $\sim 50 \%$, respectively. The majority of these centers have adopted potent induction immunotherapy involving T-cell depletion and tumor necrosis factor $\alpha$ inhibition $[7,12]$.

Thus, allogeneic islet transplantation is already a realistic approach to a diabetes cure in some centers with extensive experience. More importantly, the results from the international cohort studies and the recent phase 3 international multicenter clinical trial indicate that allogeneic islet transplantation can offer freedom from life-threatening severe hypoglycemia for type 1 diabetes patients with problematic hypoglycemia, even in non-responders to the latest technology-based treatments.

\section{LESSONS FROM CLINICAL ISLET AUTOTRANS- PLANTATION}

The outcome of allogeneic islet transplantation is complicated by a number of insults, such as alloimmunity, autoimmune recurrence, and the toxicity of immunosuppressive treatments. Therefore, the maximum potential of islet transplantation can be estimated by reviewing the outcome of clinical IAT, which is not subject to immune rejection, recurrent autoimmunity, or the $\beta$-cell toxicity of immunosuppressants. IAT is performed when the pancreas is removed to treat benign pancreatic diseases. In chronic pancreatitis with intractable abdominal pain, IAT after total pancreatectomy is already a standard therapy in available centers [9]. In this setting, a modest islet mass, typically a dose of 5,000 islet equivalents (IE)/kg, can secure complete or partial islet graft function, as defined by the use of only long-acting basal insulin and an $\mathrm{HbA}$ ic of $<7 \%$, in $68 \%$ of patients at 5 years and in $57 \%$ at 10 years post-transplant, although an immediate blood-mediated inflammatory reaction is still a concern [4].
Recently, the efficacy of closed-loop insulin delivery was investigated in the setting of total pancreatectomy with IAT. This pilot study randomized 14 adult subjects into a group receiving subcutaneous insulin via closedloop insulin delivery $(\mathrm{n}=7)$ or a control group receiving multiple daily injections with blind continuous glucose monitoring $(\mathrm{n}=7)$ for 72 hours at the transition from intravenous to subcutaneous insulin after IAT. The closed-loop insulin delivery group showed significantly lower mean serum glucose values than the control group ( $111 \pm 4 \mathrm{mg} / \mathrm{dL}$ vs. $130 \pm 13 \mathrm{mg} / \mathrm{dL}, p=0.003)$ without increased risk of hypoglycemia (percentage of time $<70 \mathrm{mg} / \mathrm{dL}: 1.9 \%$ in the closed-loop insulin delivery group vs. $4.8 \%$ in the control group, $p=0.46$ ). This pilot study showed significant promise for safely maintaining euglycemic targets during the period of islet engraftment following islet transplantation with closed-loop insulin delivery. Moreover, the results of this study suggest that islet transplantation and closed-loop insulin delivery can be mutually complementary approaches, rather than competitive therapies [17].

Considering the proven efficacy of IAT in intractable chronic pancreatitis, we examined the efficacy of IAT after partial pancreatectomy for the treatment of benign tumors in both clinical and experimental settings. We reported the outcomes of 20 patients who underwent IAT after 50\% to 60\% partial pancreatectomy. Although the 7-year diabetes-free survival rate did not differ in the control and IAT groups, prolonged diabetes-free survival was observed in patients who underwent IAT when a high islet yield (> 5,154 IE/g pancreas) during islet isolation was achieved [10].

Our previous studies revealed that the islet yield and islet function in this clinical setting was superior to those of allogeneic islet transplantation, in which islets are isolated from brain-dead donors [18]. Additionally, we showed that transplanted islets can promote the regeneration of endogenous $\beta$-cells in experimental models of IAT after partial pancreatectomy [19]. The current experimental and clinical evidence supporting this approach are summarized in Table 2 [10,18-21].

In summary, IAT after partial pancreatectomy for benign tumors could be a promising indication for clinical islet transplantation. In this setting, IAT may improve the metabolic milieu after pancreatic resection and offers a unique opportunity to understand the biological 
Table 2. The experimental and clinical evidence supporting islet autotransplantation in partial pancreatectomy for benign pancreatic tumors

\begin{tabular}{ll}
\hline Experimental evidence & Transplanted islets can promote the regeneration of endogenous $\beta$-cells [19]. \\
& Co-culture with mature islet cells augments the differentiation of insulin-producing cells \\
& from pluripotent stem cells [20]. \\
& Prolonged diabetes-free survival in patients who underwent IAT when a high islet yield \\
Clinical evidence & $(>5,154$ islet equivalents per gram of pancreas) during the islet isolation was achieved [10]. \\
& Superior islet yield and function from the living donor when compared to those of islets \\
& from the brain-dead donors [18]. \\
& Healthy twin birth after autologous islet transplantation in a pancreatectomized patient due \\
& to a benign tumor $[21]$.
\end{tabular}

IAT, islet autotransplantation.

effects of intraportal islet transplantation beyond the simple replacement of islet cell mass.

\section{CONCLUSIONS}

Recent results from international cohort studies and the phase 3 clinical trial of allogeneic islet transplantation prompt reappraisal of this method as an important component of the stepwise approach to the treatment of problematic hypoglycemia. The 5-year insulin-independence rate of islet transplantation patients has also improved at some experienced centers. IAT has already been proven to be an effective therapy for intractable pain due to advanced chronic pancreatitis. We suggest that partial pancreatectomy for the treatment of benign pancreatic tumors could be another indication for the use of IAT in the near future.

\section{Conflict of interest}

No potential conflict of interest relevant to this article was reported.

\section{Acknowledgments}

This study was supported by a grant from the Korean Health Technology R\&D Project, Ministry of Health and Welfare, Republic of Korea (HI13Co954).

\section{REFERENCES}

1. Shapiro AM, Lakey JR, Ryan EA, et al. Islet transplantation in seven patients with type 1 diabetes mellitus using a glucocorticoid-free immunosuppressive regimen. N Engl
J Med 2000;343:230-238.

2. Kim JH, Kim KW. History, current status and perspective of islet transplantation. Korean J Med 2008;75:274-279.

3. Kim KW. Islet transplantation: a realistic alternative for the treatment of insulin deficient diabetes mellitus. Diabetes Res Clin Pract 2004;66 Suppl 1:S11-S17.

4. Dunn TB, Kirchner V, Bellin MD. Beta-cell replacement therapy: current outcomes and future landscape. Curr Opin Organ Transplant 2015;20:681-690.

5. Choudhary P, Rickels MR, Senior PA, et al. Evidence-informed clinical practice recommendations for treatment of type 1 diabetes complicated by problematic hypoglycemia. Diabetes Care 2015;38:1016-1029.

6. Venstrom JM, McBride MA, Rother KI, Hirshberg B, Orchard TJ, Harlan DM. Survival after pancreas transplantation in patients with diabetes and preserved kidney function. JAMA 2003;290:2817-2823.

7. Barton FB, Rickels MR, Alejandro R, et al. Improvement in outcomes of clinical islet transplantation: 1999-2010. Diabetes Care 2012;35:1436-1445.

8. Hering BJ, Clarke WR, Bridges ND, et al. Phase 3 trial of transplantation of human islets in type 1 diabetes complicated by severe hypoglycemia. Diabetes Care 2016;39:1230-1240.

9. Matsumoto S. Clinical allogeneic and autologous islet cell transplantation: update. Diabetes Metab J 2011;35:199206.

10. Jin SM, Oh SH, Kim SK, et al. Diabetes-free survival in patients who underwent islet autotransplantation after $50 \%$ to $60 \%$ distal partial pancreatectomy for benign pancreatic tumors. Transplantation 2013;95:1396-1403.

11. Ryan EA, Paty BW, Senior PA, et al. Five-year follow-up after clinical islet transplantation. Diabetes 2005:54:2060- 
2069.

12. Bellin MD, Barton FB, Heitman A, et al. Potent induction immunotherapy promotes long-term insulin independence after islet transplantation in type 1 diabetes. Am J Transplant 2012;12:1576-1583.

13. Lehmann R, Graziano J, Brockmann J, et al. Glycemic control in simultaneous islet-kidney versus pancreas-kidney transplantation in type 1 diabetes: a prospective 13year follow-up. Diabetes Care 2015;38:752-759.

14. Lablanche S, Borot S, Wojtusciszyn A, et al. Five-year metabolic, functional, and safety results of patients with type 1 diabetes transplanted with allogenic islets within the Swiss-French GRAGIL network. Diabetes Care 2015;38:1714-1722.

15. Yang TY, Oh SH, Jeong IK, et al. First human trial of pancreatic islet allo-transplantation in Korea: focus on re-transplantation. Diabetes Res Clin Pract 2002;56:107113.

16. Yang HK, Ham DS, Park HS, et al. Reversal of hypoglycemia unawareness with a single-donor, marginal dose allogeneic islet transplantation in Korea: a case report. J Korean Med Sci 2015;30:991-994.

17. Forlenza GP, Nathan BM, Moran AM, et al. Successful application of closed-loop artificial pancreas therapy after islet autotransplantation. Am J Transplant 2016;16:527-534.

18. Jung HS, Choi SH, Kim SJ, et al. A better yield of islet cell mass from living pancreatic donors compared with cadaveric donors. Clin Transplant 2007;21:738-743.

19. Jung HS, Ahn YR, Oh SH, et al. Enhancement of beta-cell regeneration by islet transplantation after partial pancreatectomy in mice. Transplantation 2009;88:354-359.

20. Oh BJ, Oh SH, Choi JM, et al. Co-culture with mature islet cells augments the differentiation of insulin-producing cells from pluripotent stem cells. Stem Cell Rev 2015;11:62-74.

21. Jung HS, Choi SH, Noh JH, et al. Healthy twin birth after autologous islet transplantation in a pancreatectomized patient due to a benign tumor. Transplant Proc 2007;39:1723-1725. 